\title{
Erratum to "Various Empirical Equations to Unify between the Gravitational Force and the Electromagnetic Force" [Journal of Modern Physics 12 (2021) 859-869]
}

\section{Tomofumi Miyashita}

Miyashita Clinic, Osaka, Japan

Email: tom_miya@plala.or.jp

How to cite this paper: Miyashita, T. (2021) Erratum to "Various Empirical Equations to Unify between the Gravitational Force and the Electromagnetic Force" [Journal of Modern Physics 12 (2021) 859-869]. Journal of Modern Physics, 12, 1160-1161. https://doi.org/10.4236/jmp.2021.128069

Received: June 4, 2021

Accepted: June 18, 2021

Published: June 21, 2021

Copyright $\odot 2021$ by author(s) and Scientific Research Publishing Inc. This work is licensed under the Creative Commons Attribution International License (CC BY 4.0).

http://creativecommons.org/licenses/by/4.0/

\begin{abstract}
The original online version of this article (Miyashita, T. (2021) Various Empirical Equations to Unify between the Gravitational Force and the Electromagnetic Force, Journal of Modern Physics, Vol. 12, 859-869.

https://doi.org/10.4236/jmp.2021.127054) unfortunately contains the very important mistakes. The author discovered the possible problem in Equation (26) shown in Appendix. To fix the problem, the author wishes to change Equation (2) and make it more accurate.
\end{abstract}

\section{Keywords}

Erratum

1) Page 2 Equation (2) should be revised to the following:

$$
\frac{G m_{p}^{2}}{\frac{e^{2}}{4 \pi \varepsilon_{0}}}=\frac{4.5}{2 \pi} \times \frac{m_{e}}{e} \times h c \times\left(1 \frac{\mathrm{C}}{\mathrm{J} \cdot \mathrm{m}} \times \frac{1}{1 \mathrm{~kg}}\right)
$$

where $h$ is the Planck constant.

2) So, the following Equation (12) cannot be used.

$$
\hbar c=\left(\frac{e^{2}}{4 \pi \varepsilon_{0}}\right)^{\frac{1}{2}}\left(\frac{q_{m}^{2}}{\mu_{0} \pi}\right)^{\frac{1}{2}}
$$

Then,

$$
\frac{G m_{p}^{2}}{\frac{e^{2}}{4 \pi \varepsilon_{0}}}=\frac{1.8672 \times 10^{-64}}{2.3071 \times 10^{-28}}=8.0936 \times 10^{-37}
$$




$$
\frac{m_{e}}{e} \times h c=\frac{9.1094 \times 10^{-31}}{1.6022 \times 10^{-19}} \times 1.9864 \times 10^{-25}=1.1294 \times 10^{-36}
$$

Regarding the factor of 9/2, we used 4.48870 instead of 4.5. Regarding the factor of $\pi$, we used 3.13189 instead of 3.14159. So,

$$
\begin{gathered}
\frac{4.5}{2 \pi}=\frac{4.48870}{2 \times 3.13189}=0.71661 \\
\frac{4.5}{2 \pi} \times \frac{m_{e}}{e} \times h c=0.71661 \times 1.1294 \times 10^{-36}=8.0936 \times 10^{-37}
\end{gathered}
$$

Equation (D) is equal to Equation (A). Therefore, the compensation method is perfect.

Equation (2) should be changed, but any other equations can be unchanged. 